\title{
Pengaruh Perlakuan Temperatur dan Waktu Penahanan Pack Carburizing Terhadap Umur Lelah Baja St 42
}

\author{
K Suarsana ${ }^{1)^{*}}$, Cok Istri Putri $\mathrm{K}^{2)}$, I Made Astika ${ }^{3)}$ \\ 1,2,3) Jurusan Teknik Mesin Universitas Udayana, Kampus Bukit Jimbaran Bali 80362
}

doi: 10.24843/JEM.2018.v11.i01.p05

\begin{abstract}
Abstrak
Pack carburizing merupakan suatu proses laku panas untuk memperoleh pengerasan hanya pada bagian permukaan dengan menggunakan media carburizer padat. Dengan memberikan temperatur pemanasan dan waktu penahanan yang tepat diharapkan dapat meningkatkan umur lelah suatu material baja St.42. Metode pada penelitian ini menggunakan pack carburizing padat berupa serbuk, yang dibuat dalam bentuk kotak dan di dalamnya diisi serbuk carbon. Penelitian ini membahas tentang pengaruh waktu penahanan dan temperatur pack carburizing terhadap umur lelah baja ST 42 dengan menggunakan variasi temperatur pemanasan adalah : 850, 900 dan $950^{\circ} \mathrm{C}$ dan waktu penahanan 4,6 dan 8 jam. Kedua variabel ini diamati pengaruhnya terhadap umur lelah. Berdasarkan hasil penelitian bahwa waktu penahanan dan temperatur pack carburizing berpengaruh nyata terhadap umur lelah, dimana umur lelah tertinggi yaitu pada $\mathbf{9 9 3 . 0 8 9}$ cycle pada temperatur pemanasan $950^{\circ} \mathrm{C}$ dan waktu penahanan 8 jam. Umur lelah paling rendah adalah 440.613 cycle terjadi pada temperatur pemanasan $850^{\circ} \mathrm{C}$ dan waktu penahanan 4 jam.
\end{abstract}

Kata kunci : Pack carburizing, Carburizer, Umur lelah

Abstract

Pack carburizing is a hot-selling process to obtain only hardening on the surface by using solid carburizer media. Providing proper heating temperature and retention time is expected to increase the fatigue life of a steel material of St.42. The method in this study using a solid pack carburizing of powder, which is made in the form of a box and inside it is filled with carbon powder. This study discusses the effect of detention time and pack carburizing temperature on ST 42 fat age by using variation of heating temperature are: 850,900 and $950^{\circ} \mathrm{C}$ and holding time 4,6 and 8 hours. Both of these variables were observed to influence the fatigue life. Based on the result of research that the holding time and temperature of pack carburizing have a significant effect on fatigue life, where the highest fatigue age is 993,089 cycles at heating temperature $950{ }^{\circ} \mathrm{C}$ and 8 hours of detention time. The lowest fatigue period was 440,613 cycles occurring at a heating temperature of $850{ }^{\circ} \mathrm{C}$ and a 4 hour detention time.

Keyword: Pack Carburizing, Carburizer, Fatigue life

\section{Pendahuluan}

Pada beberapa komponen mesin yang berputar diharuskan memiliki kekerasan yang cukup tinggi pada permukaannya. Namun agar komponen mesin tersebut juga tangguh terhadap beban kejut dan pembebanan dinamis maka diperlukan inti yang ulet. Seperti misalnya pada poros yang sering mengalami kerusakan berupa kepatahan (fracture) akibat beban berlebih atau terjadi beban kejut. Selain itu poros juga dapat mengalami keausan akibat gesekan pada permukaannya atau bersinggungan dengan komponen mesin yang lain, seperti terjadi pada pena torak dengan dudukannya, poros engkol dengan noken as dan juga antara poros lurus dengan dudukan roda gigi atau bantalan. Untuk mengatasi permasalahan tersebut maka dilakukan proses pengerasan permukaan (case hardening). Dengan pengerasan permukaan diperoleh kekerasan yang tinggi pada bagian permukaan sedangkan bagian dalam (inti) masih tetap ulet, sehingga material menjadi lebih tahan terhadap beban gesek dan juga tangguh dalam menerima beban dinamis atau beban kejut. Ada beberapa faktor yang mempengaruhi hasil dari pack carburizing antara lain adalah waktu penahanan dan temperatur, karena kadar karbon dan tebal lapisan yang dihasilkan dari proses pack carburizing tergantung pada temperatur dan lama waktu penahanan [1]. Pengerasan permukaan dapat dilakukan dengan beberapa cara, salah satu diantaranya adalah dengan pack carburizing. Pack carburizing adalah metode pengerasan permukaan dengan mengubah komposisi kimia permukaan bahan dengan menambah kadar karbon, biasanya dilakukan pada baja. Baja yang di pack carburizing adalah baja karbon rendah dengan kandungan karbon $\leq 0,3 \%$. Salah satu baja yang tergolong ke dalam baja kadar rendah dan sering digunakan sebagai bahan poros adalah baja ST 42 [2]

Dari uraian diatas menjadi sangat perlu mengangkat permasalahan tentang bagaimana pengaruh variasi waktu penahanan (holding time) dan temperatur pack carburizing terhadap umur lelah baja ST 42

\section{Metode Penelitian}

\subsection{Material Uji}

Bahan yang digunakan dalam penelitian ini adalah baja ST 42 yang memiliki komposisi kimia antara lain : karbon (C) 0,25\%, mangan (Mn) 0,80\%, silikon (Si) $0,30 \%$ dan sisanya besi $(\mathrm{Fe})[3\}$. 


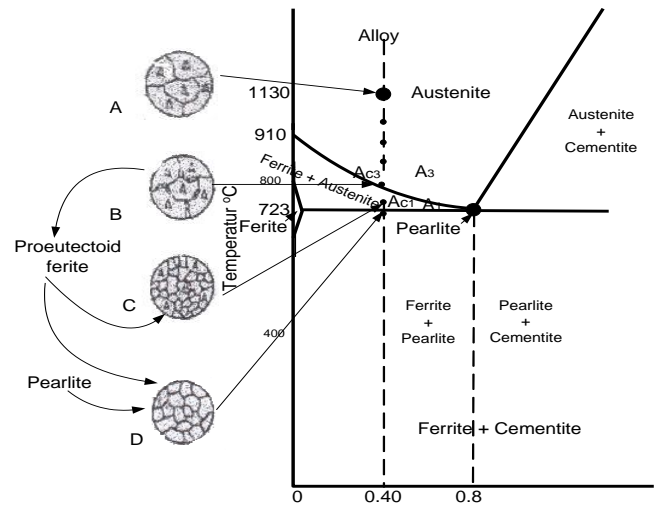

Gambar 1. Diagram $\mathrm{Fe}-\mathrm{Fe}_{3} \mathrm{C}$ Baja Karbon (Avner, Sidney H:1987, Hal.78)

\section{Carburizer}

Pada proses pack carburizing, carburizer mempunyai peranan yang sangat penting. Untuk itu dalam pemilihan komposisi dari carburizer harus tepat agar mandapatkan hasil yang memuaskan. Biasanya komposisi carburizer terdiri dari carburizer padat seperti charcoal, coke dan lainnya (umumnya terdapat dalam arang kayu) [4]. Sebagai energizer biasanya digunakan barium karbonat dan kalsium karbonat. Komposisi dari carburizer dapat dilihat pada tabel 2.1.

Tabel 1. Komposisi Carburizer Padat.

\begin{tabular}{|l|lc|}
\hline $\begin{array}{c}\text { Case } \\
\text { hardening }\end{array}$ & Ingredients & Parts by weight (\%) \\
\hline $\begin{array}{l}\text { Compound } \\
\text { no. } 1 \text { and } \\
2\end{array}$ & Charcoal & 90 \\
& Sodium karbonat & \\
& & \\
\cline { 2 - 3 } Compound & Barium karbonat+ charcoal & $90+10$ \\
no. 3 & $\left(\mathrm{Na}_{2} \mathrm{CO}_{3}+\right.$ binder or $\left.\mathrm{BaCO}_{3}\right)$ & 4 \\
\cline { 2 - 3 } & Charcoal & 50 \\
& Coke & 30 \\
& Barium karbonat & 12 \\
& Sodium karbonat & 3 \\
& Kalsium karbonat & 3 \\
& Binder & 2 \\
\hline
\end{tabular}

Sumber : (Prabhudev, K.H, hal.305).

Kemudian material dibentuk menjadi spesimen uji lelah berdasarkan spesimen standar mesin uji rotating bending fatigue dari Coustesy of Fatigue Dynamics, $\operatorname{lnc}[7]$.

\section{Mekanisme Patah Lelah}

Proses terjadinya patah lelah secara garis besar dibagi menjadi tiga tahapan, yaitu :

- Tahap awal retakan (crack initiation)

- Tahap perambatan retak (crack propagation)

- Tahap patah akhir

Awal retakan umumnya dimulai dari permukaan, hal ini terjadi karena permukaan menerima gaya terbesar dan sering mendapat konsentrasi tegangan akibat perubahan geometri, jika tegangan maksimum berada diatas kekuatan material, maka akan terjadi konsentrasi tegangan yang meningkat pada ujung retakan sehingga retakan itu akan merambat.
Mekanisme perambatan retak dapat dilihat seperti gambar berikut [5] [6].

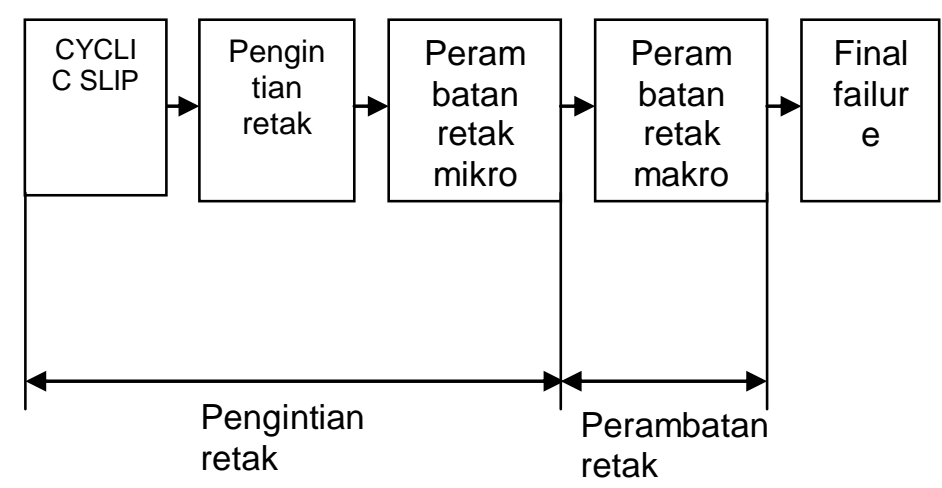

Gambar 2. Mekanisme Perambatan Retak (Fuchs, H.O : 1980)

Alat penelitian :

1. Carburizer:

Arang kayu $\quad=80 \%$ berat

Barium karbonat $\left(\mathrm{BaCO}_{3}\right)=15 \%$ berat

Kalsium karbonat $\left(\mathrm{CaCO}_{3}\right)=5 \%$ berat

2. Kotak Pack Carburizing

3. Dapur pemanas

4. Mesin uji fatik

5. Mesin Polishing

Proses Pack Carburizing :

1. Masukkan spesimen / benda uji dan campuran carburizer kedalam kotak, dimana penempatan antara spesimen yang satu dengan yang lain berjarak sama, kemudian ditutup rapat (kedap udara).

2. Selanjutnya kotak tersebut dimasukkan ke dalam dapur pemanas.

3. Hidupkan dapur pemanas hingga mencapai temperatur tertentu dan ditahan pada temperatur tersebut selama beberapa jam sesuai dengan kebutuhan.

4. Setelah itu kotak dikeluarkan dan didinginkan di udara bebas.

5. Spesimen dikeluarkan dan dibersihkan untuk selanjutnya dilakukan pengujian.

\section{Pengujian fatik rotating bending :}

1. Spesimen uji dijepit pada poros yang berputar pada salah satu ujungnya, sedangkan ujung yang lain diberikan beban.

2. Kecepatan putaran poros $1890 \mathrm{rpm}$.

3. Besarnya beban yang diberikan adalah $15 \mathrm{Kgf}$.

4. Setelah spesimen uji dipasang pada mesin dengan tepat, lalu mesin ditutup dengan alat peredam suara kemudian mesin dihidupkan.

5. Dalam beberapa waktu spesimen uji akan patah, mesin akan berhenti secara otomatis dan nilai akhir akan terbaca pada alat pencatat dalam satuan cycle. 


\section{Prosedur Penelitian}

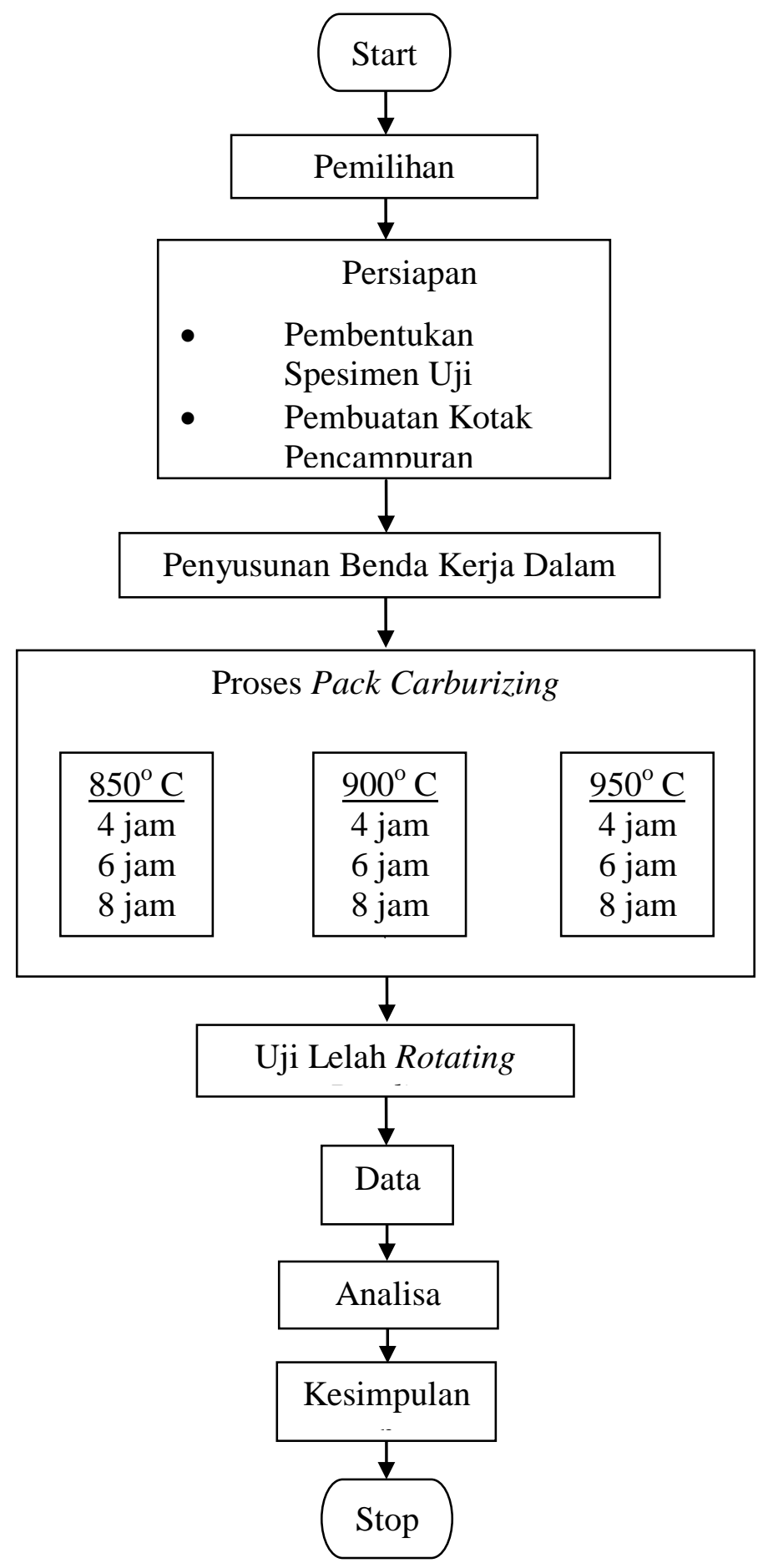

Gambar 3. Alur Penelitian

\section{Hasil dan Pembahasan}

3.1. Pengaruh temperatur dan waktu penahanan Pack Parburizing terhadap umur lelah Baja St.42

Dari pengujian yang telah dilakukan, dengan temperature 850,900 dan $950^{\circ} \mathrm{C}$ terhadap umur lelah baja St. diperoleh data seperti pada Tabel 1.
Tabel 1 Data uji dari Umur lelah baja St. 42

\begin{tabular}{|c|c|c|c|c|}
\hline \multirow{3}{*}{$\begin{array}{c}\text { Temperatur } \\
\text { (A) }\end{array}$} & \multicolumn{3}{|c|}{$\begin{array}{l}\text { Waktu Penahanan } \\
\text { (holding time) }\end{array}$} & \multirow[t]{3}{*}{ Jumlah } \\
\hline & \multicolumn{3}{|c|}{ (B) } & \\
\hline & 4 jam & 6 jam & 8 jam & \\
\hline & 480.562 & 556.076 & 730.895 & \\
\hline & 440.613 & 600.453 & 681.457 & \\
\hline $8500 \mathrm{C}$ & 501.108 & 526.523 & 650.987 & \\
\hline Jumlah & 1.422 .283 & 1.683 .052 & 2.063 .339 & 5.168 .674 \\
\hline \multirow[t]{3}{*}{ Rata-rata } & 474.094 & 561.017 & 687.78 & \\
\hline & 626.139 & 667.785 & 788.865 & \\
\hline & 585.112 & 631.34 & 790.801 & \\
\hline $9000 \mathrm{C}$ & 628.334 & 692.99 & 811.32 & \\
\hline Jumlah & 1.839 .585 & 1.992 .115 & 2.390 .986 & 6.222 .686 \\
\hline \multirow[t]{3}{*}{ Rata-rata } & 613.195 & 664.038 & 796.995 & \\
\hline & 730.65 & 940.671 & 1.150 .907 & \\
\hline & 678.905 & 1.035 .003 & 1.060 .457 & \\
\hline 950 o C & 833.032 & 897.83 & 1.267 .905 & \\
\hline Jumlah & 2.242 .587 & 2.873 .504 & 2.979.269 & 8.595 .360 \\
\hline Rata-rata & 747.529 & 957.835 & 993.089 & \\
\hline TOTAL & 5.504 .455 & 6.548 .671 & 7.933 .594 & 19.986 .720 \\
\hline $\begin{array}{l}\text { Dari } \\
\text { temperatu } \\
\text { pengaruh } \\
\text { terhadap }\end{array}$ & $\begin{array}{l}\text { Tabel } \\
\text { e terhac } \\
\text { vaktu p } \\
\text { nur lelar }\end{array}$ & $\begin{array}{c}\text { dapat } \\
\text { umur le } \\
\text { hanan } p\end{array}$ & $\begin{array}{l}\text { diuraikan } \\
\text { ah baja } \\
\text { nas pada }\end{array}$ & $\begin{array}{l}\text { pengaruh } \\
\text { t. } 42 \text { dan } \\
\text { baja St.42 }\end{array}$ \\
\hline
\end{tabular}

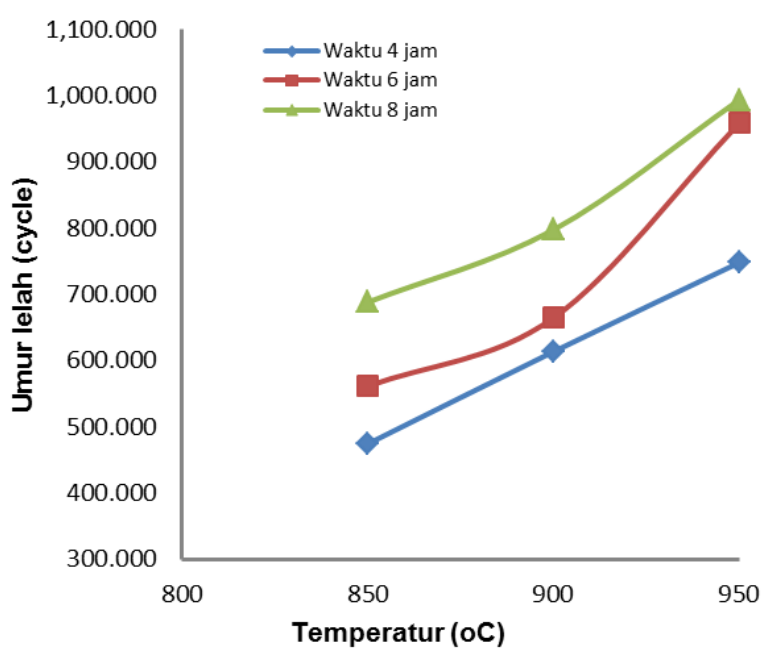

Gambar 4. Hubungan temperature terhadap umur lelah

Secara numerik terlihat pada Gambar 4 bahwa ada peningkatan umur lelah dari setiap perlakuan dengan meningkatnya temperatur pack karburizing. Pada temperatur $850{ }^{\circ} \mathrm{C}$ dan waktu penahanan memberikan nilai umur lelah berturut-turut dari : 4 jam memberikan nilai umur lelah 474.094 cycle, dengan waktu penahanan 6 jam memberikan nilai umur lelah 561.017 cycle, dan dengan waktu penahanan 8 jam memberikan nilai umur lelah 678.780 cycle. Pada 
temperatur $900{ }^{\circ} \mathrm{C}$ dan waktu penahanan 4 jam memberikan nilai umur lelah 613.195 cycle, dengan waktu penahanan 6 jam memberikan nilai umur lelah 664.038 cycle, dan dengan waktu penahanan 8 jam memberikan nilai umur lelah 796.995 cycle. Pada temperatur $950{ }^{\circ} \mathrm{C}$ dan waktu penahanan 4 jam memberikan nilai umur lelah 747.529 cycle, dengan waktu penahanan 6 jam memberikan nilai umur lelah 957.835 cycle, dan dengan waktu penahanan 8 jam memberikan nilai umur lelah 993.089 cycle.

\subsection{Pengaruh waktu penahanan Pack Parburizing}

Gambar 5 menunjukkan bahwa ada peningkatan umur lelah dari setiap perlakuan dengan meningkatnya waktu penahanan panas pack karburizing.

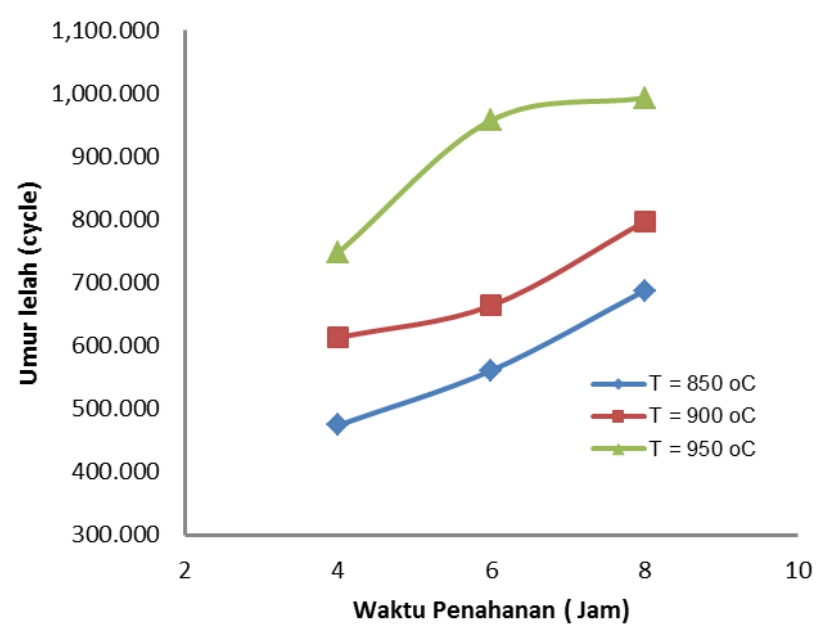

Gambar 5. Hubungan waktu penahanan terhadap umur lelah

Umur lelah meningkat dari rata-rata 474.094 cycle (temperatur $850{ }^{\circ} \mathrm{C}$, waktu penahanan 4 jam) menjadi rata-rata 993.089 cycle (temperatur $950{ }^{\circ} \mathrm{C}$, waktu penahanan 8 jam). Hal ini disebabkan dengan meningkatnya temperatur pack carburizing maka atom karbon (yang berasal dari carburizer) akan semakin mudah untuk berdifusi ke permukaan baja, karena pada kondisi tersebut tingkat kelarutan baja dalam bentuk larutan austenit semakin tinggi. Begitu juga dengan semakin bertambahnya waktu penahanan (holding time) maka semakin memberikan waktu terhadap atom karbon untuk berdifusi masuk ke permukaan baja, sehingga permukaan baja menjadi lebih keras. Dengan meningkatnya kekerasan pada permukaan maka umur lelahnyapun akan meningkat. Pada benda uji dinamis (material yang diberikan pengujian dengan beban kelelahan) mempunyai patahan yang berbeda dengan benda uji statis (tarik),

dimana pada benda uji dinamis permukaan patah terdapat alur retak dan bidang patahannya tampak lebih kasar atau berserabut (fibrous) serta tidak terdapat necking ( pengecilan permukaan patahan ) seperti pada pengujian statis (tarik)

\section{Simpulan}

Berdasarkan hasil pengujian dan analisa tentang pengaruh variasi waktu penahanan (holding time) dan temperatur pack carburizing terhadap umur baja ST 42, maka :

1. Waktu penahanan (holding time) pack carburizing berpengaruh nyata terhadap umur lelah Baja ST 42, semakin lama waktu penahanan maka umur lelahnya mengalami peningkatan. Rata-rata peningkatan umur lelah tiap perlakuan waktu penahanan adalah 134.954 cycle.

2. Temperatur pack carburizing memberikan pengaruh nyata terhadap umur lelah Baja ST 42. Hal ini dapat dilihat bahwa peningkatan umur lelah pada temperatur $850^{\circ} \mathrm{C}$ dengan variasi waktu penahanan masing-masing 4, 6 dan 8 jam umur lelahnya meningkat rata-rata 106.843 cycle. Pada temperatur $900^{\circ} \mathrm{C}$ dengan variasi waktu penahanan masing-masing 4, 6, dan 8 jam, umur lelahnya meningkat rata-rata 91.900 cycle. Pada temperatur $950^{\circ} \mathrm{C}$ dengan variasi waktu penahanan masingmasing 4, 6 dan 8 jam, umur lelahnya meningkat rata-rata 206.114 cycle.

\section{Ucapan Terima Kasih}

Terima kasih kepada kepala Laboratorium Metalurgi Fakultas Teknik Jurusan Mesin Unud, yang telah memberikan ijin kepada peneliti untuk melakukan pengujian dan kepada Kepala Laboratorium Metalurgi Institut Teknologi Malang (ITN) dalam pengujian Umur lelah bahan St 42 .

\section{Daftar Pustaka}

[1] Suherman Wahid, 1988, Ilmu Logam II, Penerbit Jurusan Teknik Mesin FTI-ITS, Surabaya.

[2] Budiman Anton, Niemann G, 1992, Elemen Mesin, Edisi II, Jilid I, PT Gelora Aksara Pratama, Jakarta

[3] Avner Sidney H, 1987, Introduction to Physical Metallurgy, Second Edition, Mc Graw-Hill International Book Company, Tokyo.

[4] Prabhudev K.H, 1988, Hand Book of Heat Treatment of Steel, Mc Graw-Hill Publishing Company Limited, New Delhi.

[5] Fuchs H.O, 1980, Metal Fatigue In Engineering, A Wiley Interscience Publication, New York.

[6] Askeland Donald R, 1984, The Science and Engineering of Material, University of Missouri-Rolla

[7] Karl E. Thelning, 1984, Steel and Its Heat Treatment, Second Edtion, Butterworths, London. 